\title{
Prognostic Role of Soluble Urokinase Plasminogen Activator Receptor at the Emergency Department: A Position Paper by the Hellenic Sepsis Study Group
}

\author{
Dimitrios Velissaris · George Dimopoulos · John Parissis · Zoi Alexiou • Nikolaos Antonakos • \\ Dimitrios Babalis - Styliani Gerakari - Vassileios Kaldis • Pantelis Koutoukas • Malvina Lada • \\ Konstantinos Leventogiannis · Ioannis Pantazopoulos • Antonios Papadopoulos • \\ Eftihia Polyzogopoulou • Charalambos Gogos · Apostolos Armaganidis · Evangelos J. Giamarellos-Bourboulis
}

Received: March 5, 2020 / Published online: May 12, 2020

(C) The Author(s) 2020

\section{ABSTRACT \\ In light of the accumulating evidence on the negative predictive value of soluble urokinase plasminogen activator receptor (suPAR), a group of experts from the fields of intensive care medicine, emergency medicine, internal medi- cine and infectious diseases frame a position}

Digital Features To view digital features for this article go to https://doi.org/10.6084/m9.figshare.12206708.

D. Velissaris · C. Gogos

Department of Internal Medicine and Department of Emergency Medicine, University of Patras, Patras, Greece

G. Dimopoulos · A. Armaganidis

Second Department of Critical Care Medicine, Medical School, National and Kapodistrian

University of Athens, Athens, Greece

J. Parissis · E. Polyzogopoulou

Department of Emergency Medicine, Medical School, National and Kapodistrian University of Athens, Athens, Greece

\section{Z. Alexiou}

Second Department of Internal Medicine, Thriasio Elefsis General Hospital, Elefsina, Greece

N. Antonakos · K. Leventogiannis .

A. Papadopoulos · E. J. Giamarellos-Bourboulis ( $\square)$ Fourth Department of Internal Medicine, Medical School, National and Kapodistrian University of Athens, Athens, Greece e-mail: egiamarel@med.uoa.gr statement on the role of suPAR in the screening of patients admitted to the emergency department. The statement is framed taking into consideration existing publications and our own research experience. The main content of this statement is that sUPAR is a non-specific marker associated with a high negative predictive value for unfavourable outcomes; levels < $4 \mathrm{ng} / \mathrm{ml}$ indicate that it is safe to discharge the patient, whereas levels $>6 \mathrm{ng} / \mathrm{ml}$ are an alarming sign of risk for unfavourable outcomes.

\section{Babalis}

Department of Emergency Medicine, Larissa General Hospital Koutlibaneion-Triantafyllion, Larissa, Greece

S. Gerakari

Department of Emergency Medicine, Tzaneion Piraeus General Hospital, Piraeus, Greece

V. Kaldis

Department of Emergency Medicine, Sismanogleion Athens General Hospital, Athens, Greece

P. Koutoukas

Department of Emergency Medicine, Sparti General Hospital, Sparti, Greece

M. Lada

Second Department of Internal Medicine,

Sismanogleion General Hospital, Athens, Greece

I. Pantazopoulos

Department of Emergency Medicine, University General Hospital of Larissa, School of Medicine, University of Thessaly, Larisa, Greece 
However, the suPAR levels should always be interpreted in light of the patient's history.

Keywords: Emergency department; Mortality; suPAR; Triage

\section{Key Summary Points}

suPAR is a non-specific marker associated with a high negative predictive value for unfavourable outcome.

Levels $<4 \mathrm{ng} / \mathrm{ml}$ allow discharge of the patient admitted to the ED after thorough clinical evaluation.

Levels $>6 \mathrm{ng} / \mathrm{ml}$ are an alarming sign of risk for unfavourable outcome but need to be interpreted in light of the patient's history.

Levels between 4 and $6 \mathrm{ng} / \mathrm{ml}$ need to be interpreted in light of the patient's history of comorbidities, which may increase them, such as rheumatoid arthritis, solid tumour malignancy and chronic renal disease.

Levels $>12 \mathrm{ng} / \mathrm{ml}$ in critically ill patients are prognostic of 28-day mortality ranging between 17 and 50\% depending on the APACHE II score.

\section{INTRODUCTION}

Early risk detection is the main purpose of personnel committed to the triage of patients admitted to the emergency department (ED) of all secondary and tertiary hospitals. Successful triage may affect final outcomes. The difficulty to triage often increases when clinical signs and symptoms are subtle or unspecific. Nowadays, biomarkers are introduced to better screen the risk of death for patients with subtle or unspecific signs.
The Hellenic Sepsis Study Group (HSSG) (https://www.sepsis.gr) has been active since 2006 and aims to improve the early diagnosis and management of sepsis. The clinical development of surrogate tools for the definition of sepsis risk is one of the major aims of the HSSG. Since the group has shown long-term expertise in the clinical value of suPAR (soluble urokinase plasminogen activator receptor), we decided to frame a position paper on the role of suPAR in the early detection of risk of unfavourable outcome for patients admitted to the ED.

\section{METHODS}

A panel of 16 experts who actively participate in the HSSG were called to participate. They were five intensivists (AA, DB, GD, SG, VK, DV), one cardiologist (JP), two ED physicians (IP and EP), four infectious diseases exerts (CG, EJGB, ML and $\mathrm{AP}$ ) and four internists (ZA, NA, KL and PK) with vast $\mathrm{ED}$ experience. An initial e-mail invitation was sent on 17 November 2019 to all 16 experts explaining that the paper would be composed of positions on: (1) the biological role of the uPAR/suPAR and the diagnostic and prognostic utility for infectious and non-infectious disorders; (2) the diagnostic and prognostic utility of suPAR in sepsis; (3) the diagnostic utility of guiding treatment in the ED. Three members of the panel (DV, GD and EJGB) were delegated to draft the respective position statements according to their research expertise.

The panel experts met in person on 28 November 2019 where each of the three delegates presented their statement orally followed by discussion. It was decided that each statement and the main discussion points would be the core of the manuscript. The next meeting took place on 25 January 2020. Before the meeting, the manuscript draft was distributed to all members of the panel. During the meeting, all experts provided their comments and finalized the manuscript. The final published statement was a consensus of all meeting participants. This article is based on previously conducted studies and does not contain any studies with human participants or animals performed by any of the authors. 


\section{POSITION 1}

\section{The Biological Role of the uPAR/suPAR and the Diagnostic and Prognostic Utility for Infectious and Non-Infectious Disorders}

suPAR is the soluble counterpart of urokinase plasminogen activator receptor ( $\mathrm{UPAR}$ ), which is a protein anchored to cell membranes by glycosyl-phospatidyl (GPI) moieties. UPAR is found in many immune cells, such as monocytes, activated lymphocytes and tissue macrophages, although it may also be present in fibroblasts and cardiomyocytes. UPAR has several functions and is involved in cell proliferation, angiogenesis and fibrinolysis. Under infectious and noninfectious inflammatory conditions, the GPI moiety that anchors UPAR to the cell is cleaved, and this leads to the release of suPAR. SUPAR may be detected in serum, plasma, cerebrospinal fluid and urine and is a marker of disease severity. suPAR has a secondary structure of 17 anti-parallel $\beta$-sheets with 3 short $\alpha$ helices. There are three homologous domains of suPAR: DI, DII and DIII. Comparing cDNA sequences, DI differs from DII and DIII in its primary and tertiary structure, yielding its distinct ligand-binding properties. We currently know that suPAR is a non-specific marker and that many conditions, both acute and chronic, may affect serum levels [1].

suPAR levels have been suggested to mirror the degree of inflammation as its concentration is associated with the activation of the immune system. suPAR levels are positively correlated with pro-inflammatory biomarkers, such as tumour necrosis factor- $\alpha$, leukocyte counts and C-reactive protein. It has also been associated with organ damage in various diseases. As such, elevated levels of suPAR are associated with increased risk of systemic inflammatory response syndrome (SIRS), cancer, focal segmental glomerulosclerosis, cardiovascular disease, type 2 diabetes, infectious diseases, HIV and mortality.

Over the last 20 years, evidence has accumulated (summarized in reviews [2-4]) showing that many disorders are accompanied by increased levels of suPAR. Among these diseases are chronic autoimmune disorders, solid tumour malignancies and chronic heart failure. More precisely, the activation of UPAR takes place at the level of the cell membrane of chondrocytes and osteocytes in patients with rheumatoid arthritis and mediated bone resorption [2]. suPAR is increased in patients with colorectal cancer, ovarian cancer, breast cancer and prostate cancer, and it is an indicator of unfavourable prognosis [3]. The implication of the uPAR/suPAR activation in malignancy is so well studied that it is even considered a novel therapeutic target [4]. Understanding of the implication of suPAR as an early prognostic marker in patients with malignancy is coming from Greece. Starting from a small number of patients who comprised a derivation cohort, the prognostic value of suPAR was studied in a validation cohort of 267 patients all suffering from chronic liver disorders. Patients with active hepatocellular carcinoma (HCC) were excluded from the study. Enrolled patients were classified as low $(n=75)$ or high risk $(n=192)$ for the development of HCC according to the criteria of the European Association for the Study of the Liver. Among those at high risk, concentrations of suPAR were greater in the group of patients who eventually developed HCC within the next 7 years. A cutoff point of $9.56 \mathrm{ng} / \mathrm{ml}$ had $90.4 \%$ sensitivity and $96.4 \%$ negative predictive value for the development of HCC within the next 7 years [5].

In a large-scale prospective study, patients who developed chronic renal disease were divided at the start of their follow-up into four quartiles of suPAR: $<2.37 \mathrm{ng} / \mathrm{ml} \quad(n=515)$, between 2.37 and $3.03 \mathrm{ng} / \mathrm{ml} \quad(n=577)$, between 3.04 and $4.02 \mathrm{ng} / \mathrm{ml}(n=601)$ and $>$ $4.02 \mathrm{ng} / \mathrm{ml}(n=599)$. The rate toward decrease of the baseline glomerular filtration rate (GFR) over the first decade of follow-up was greater among patients in the last quartile. More precisely, the annual change of GFR was $-0.9 \mathrm{ml} /$ $\mathrm{min} / 1.73 \mathrm{~m}^{2}$ among patients in the first quartile and $-4.2 \mathrm{ml} / \mathrm{min} / 1.73 \mathrm{~m}^{2}$ among patients in the fourth quartile [6]. The same four quartiles of suPAR are also predictive of the risk of developing acute renal injury among patients 
who undergo coronary angiography as a result of the contrast material used during this procedure [7]. The deterioration of renal function may come from the formation of complexes between suPAR and $\alpha_{v} \beta_{3}$ integrins on renal podocytes. This interaction is further enhanced among African Americans who carry the highrisk APOL1 genotype [8]. This effect on the glomeruli leading to proteinuria is consistent with the recently reported greater values of suPAR among patients with focal segmental glomerulosclerosis [9].

TRIAGE III is an interventional trial in Denmark where suPAR is used to improve DEPT (Danish Emergency Process Triage) used by the ED physicians. DEPT consists of a combined assessment of vital signs and symptoms and classifies patients into categories: Red (highest risk of death the next 7 days), Orange, Yellow and Green (least risk for death the next 7 days). suPAR was measured in 4420 patients and improved the prognostic performance of DEPT by moving more patients into the Red and Orange categories so that the area under the curve for 7-day mortality (receiver-operator characteristic analysis) of suPAR combined with DEPT was 0.81 compared with 0.71 for DEPT only [10]. A post-hoc analysis of the data of the TRIAGE III trial revealed that among patients who were discharged the first $24 \mathrm{~h}$, the range of suPAR was between 2.6 and $4.7 \mathrm{ng} / \mathrm{ml}$ in 30-day survivors and between 6.7 and $11.8 \mathrm{ng} / \mathrm{ml}$ in 30-day non-survivors [11]. These data support that concentrations of suPAR $<4 \mathrm{ng} / \mathrm{ml}$ are interpreted as normal and allow safe patient discharge from the ED. Concentrations $>6 \mathrm{ng} /$ $\mathrm{ml}$ are indicative of substantial risk of death. A grey zone remains for patients with values between 4 and $6 \mathrm{ng} / \mathrm{ml}$ [12].

An interesting recent publication refers to the important prognostic role of suPAR for the development of severe respiratory failure among patients admitted to the ED with pneumonia by the new coronavirus SARS-CoV-2 (COVID-19 disease). suPAR $\geq 6 \mathrm{ng} / \mathrm{ml}$ was associated with sensitivity, specificity, positive predictive value and negative predictive value of $85.7 \%, 91.7 \%, 85.7 \%$ and $91.7 \%$, respectively, for the prediction of the progression into severe respiratory failure necessitating mechanical ventilation [13].

Comment 1: The position implies that the interpretation of suPAR levels needs to be done with an individualized approach considering the history of malignancy or chronic renal disease since this may lead to increased baseline values. This, however, generates the question of the lifetime of suPAR in chronic conditions.

\section{POSITION 2}

\section{Diagnostic and Prognostic Utility of suPAR in Sepsis}

Two large clinical studies have been performed in Greece on the diagnostic and prognostic value of suPAR for sepsis. Both studies were conducted before 2016, so sepsis classification was done according to the 2003 criteria. The first study enrolled 180 patients with sepsis developing in the field of ventilator-associated pneumonia who were hospitalized in two Intensive Care Units (ICUs). suPAR was measured for 7 consecutive days. Concentrations were significantly greater among patients with severe sepsis and septic shock than among those with uncomplicated sepsis. When analysis was done for the prognosis of outcome, it was found that suPAR > $12.9 \mathrm{ng} / \mathrm{ml}$ was an independent predictor of unfavourable outcome; serum levels remained stable over the disease course. suPAR was also detected in the supernatants of isolated neutrophils of the first day of symptoms, indicating this cell type as a main reservoir of production [14].

The second study was multicenter and enrolled 1914 patients from 37 study sites of the HSSG; suPAR was measured in the serum in the first $24 \mathrm{~h}$ from the presence of signs of SIRS; in 367 patients suPAR was also measured on days 3,7 and 10 of follow-up. Patients were stratified into four strata of severity considering suPAR and the APACHE (Acute Physiology and Chronic Health Evaluation) II score; suPAR < $12 \mathrm{ng} / \mathrm{ml}$ and APACHE II $<17$; suPAR $\geq 12 \mathrm{ng} /$ $\mathrm{ml}$ and APACHE II $<17$; suPAR $<12 \mathrm{ng} / \mathrm{ml}$ and APACHE $\quad$ II $\geq 17 ; \quad$ suPAR $\geq 12 \mathrm{ng} / \mathrm{ml} \quad$ and APACHE $\quad$ II $\geq 17$. The respective 28-day 
mortality was $5.5 \%, 17.4 \%, 37.4 \%$ and $51.5 \%$; suPAR remained unchanged during follow-up of survivors and non-survivors. An independent confirmation cohort of 196 patients with severe sepsis/septic shock from Sweden was studied; the 28-day mortality for the four strata of severity was $2.0 \%, 28.6 \%, 21.3 \%$ and $33.8 \%$, respectively [15].

Comment 1: Do we have data on the suPAR clearance? Can this affect measurements and risk assessment?

Reply: Data are not available.

\section{POSITION 3}

\section{Clinical Research on Early Patient Management Guided by suPAR}

The most critical element of sepsis management is the early administration of appropriate antimicrobial therapy. This knowledge was developed from a retrospective analysis of 2713 patients in septic shock. The start of antibiotic treatment the first hour from onset of hypotension was accompanied by $79.1 \%$ survival after 28 days; each hour of delay was accompanied by a $7.6 \%$ decrease of the chances of survival [16]. This mandates the early recognition of severe infection. This is easier when signs of sepsis exist and far more difficult for patients with unspecific complaints. Since the introduction of the Sepsis-3 definitions in 2016, qSOFA (quick SOFA score) has been introduced as an early warning score in the ED. qSOFA screens for the presence of tachypnoea defined as $>22$ breaths/min, mental confusion defined as Glasgow Coma Scale $<13$ and hypotension defined as systolic blood pressure $<100 \mathrm{mmHg}$. Every patient who presents at least two of these signs has at least $10 \%$ risk of death after 28 days, whatever is defined with $90 \%$ sensitivity [17]. According to recently published data of the HSSG, even patients with a qSOFA score of 1 have a significant risk for 28-day unfavourable outcome [18]. This generates the question of whether suPAR may help trace the patients among those with one sign of qSOFA at significantly greater risk of death compared with those with one sign of qSOFA but without increased suPAR. This is the rationale of the SUPERIOR trial that is running in two study sites of the HSSG (EudraCT no. 2018-001008-13; ClinicalTrials.gov NCT03717350) [19]. In this ongoing study, enrolled patients are adults with clinical suspicion of an infection, one sign of qSOFA and $\operatorname{suPAR} \geq 12 \mathrm{ng} / \mathrm{ml}$. Patients with two or three signs of qSOFA, transplanted patients, patients with full-blown sepsis and patients with no resuscitation decision are excluded. Enrolled patients are randomized to blind treatment with placebo or with one single infusion of $2 \mathrm{~g}$ meropenem. Then, patients are returned to the triage queue already set for them. Primary study endpoint according to the last revision of the study protocol is the early worsening of the patient defined as any at least one point increase of the admission total SOFA score in the first $24 \mathrm{~h}$. Main secondary study endpoints are (1) the early worsening of the patient analyzed separately per quartile of the total SOFA score of the patient population and (2) 7-, 28-, 60- and 90-day mortality.

Comment 1: According to everyday clinical practice, pulmonary embolism is a common cause of tachypnoae. This equals 1 point of the qSOFA score. How can this be adjusted in the SUPERIOR trial?

Reply: This is why suspicion of infection is one of the inclusion criteria whereas one of the secondary endpoints is analysis among patients who eventually meet the Sepsis-3 definitions.

Comment 2: Regarding clinical practice, not the protocol per se, it needs to be emphasized that patients with 1 point of qSOFA are not septic. However, the purpose of the protocol is to identify those patients with 1 point on qSOFA who are probably at high risk of death. Proper analysis also mandates recording the time delay until the start of ED management.

\section{POINTS OF DISCUSSION}

Point 1: It is mandatory to clarify the confounding factors that may be realted to this biomarker since production may be triggered by other situations. suPAR is a non-specific marker and can only screen for the risk of unfavourable outcome without knowing what the underlying 


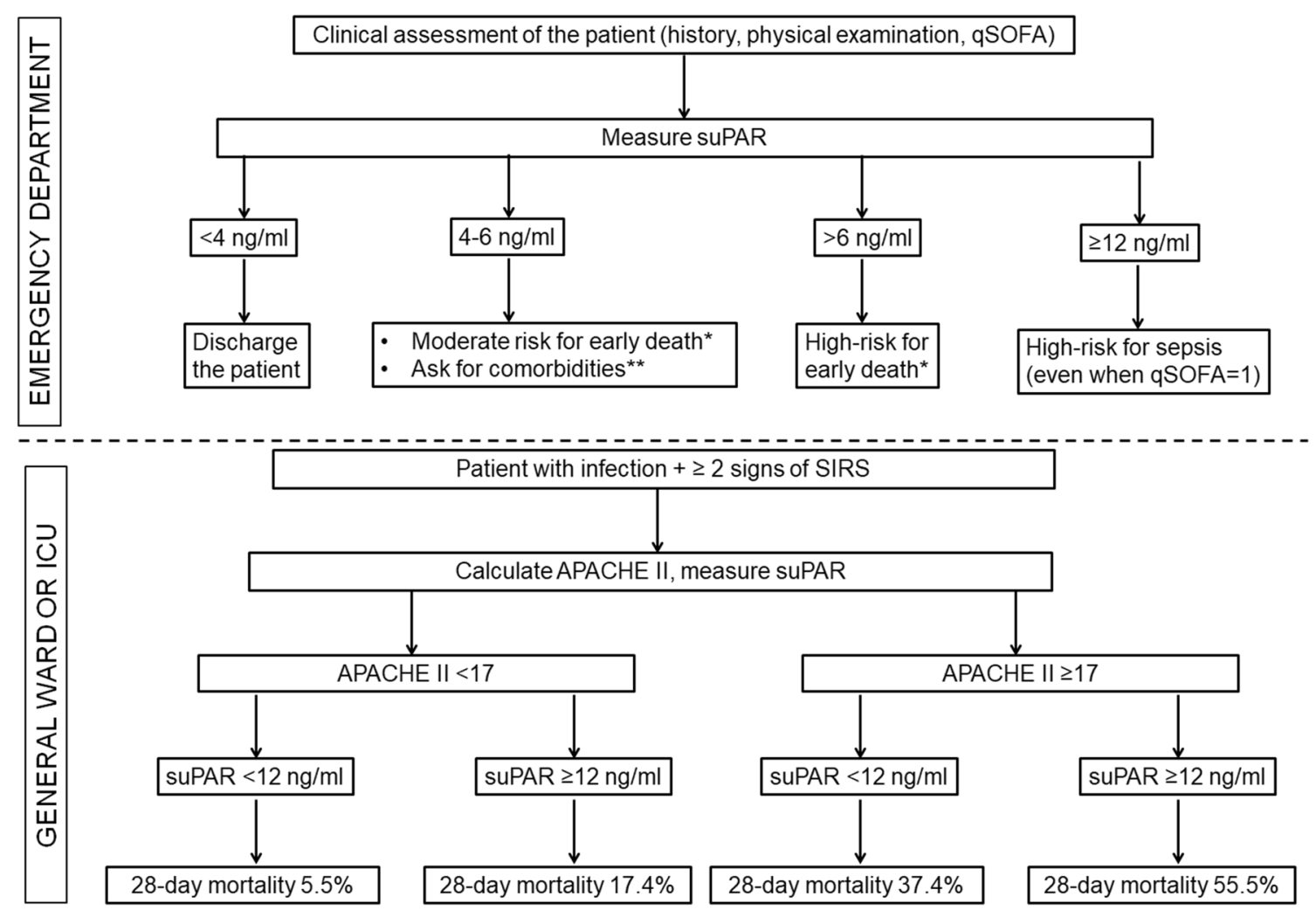

Fig. 1 Proposed algorithm for the interpretation of the values of suPAR (soluble urokinase plasminogen activator receptor) according to the level of health services. APACHE Acute Physiology and Chronic Health Evaluation, $E D$ emergency department, $I C U$ intensive care unit,

condition is. As such, it can be very useful for all patients admitted in the ED and not just for infections. I would personally favour having more research evidence on other acute conditions in the ED such as acute heart failure. I believe that the best approach is to associate cut-off concentrations of suPAR with a specific level of risk.

Point 2: In light of all that has been stated so far and taking into consideration that solid malignancies may generate higher baseline levels for patients, we believe that suPAR $\geq 12 \mathrm{ng} / \mathrm{ml}$ in oncological patients is an alarming sign of sepsis.

Point 3: We find very attractive the possibility that, among patients with one sign of qSOFA, which is usually considered nonalarming, the use of suPAR may be of considerable added value for risk definition.
qSOFA quick sequential organ failure assessment, SIRS systemic inflammatory response syndrome. ${ }^{*}$ The first 30 days. ${ }^{* *}$ Chronic renal disease, solid malignancy, chronic infection by the human immunodeficiency virus

Point 4: The overall negative predictive value of suPAR, whatever the detection of low levels means, probably $<4 \mathrm{ng} / \mathrm{ml}$, will allow the safe discharge of patients.

Point 5: In light of the very strong data for the value of suPAR as a rule-out marker, it needs to be emphasized that the biomarker still has great diagnostic validity. Looking at the same data from another point of view, there is no doubt from the clinical perspective that elevated suPAR levels in a patient with infection are compatible with sepsis.

\section{FINAL STATEMENT}

Considering all the positions and points of discussion, the following position statement 
Table 1 Expert position on the strengths and weaknesses of soluble urokinase plasminogen activator receptor (suPAR) for the prognosis of patients at the emergency department (ED)

\begin{tabular}{ll}
\hline Reference & Strengths \\
\hline$[10]$ & $\begin{array}{l}\text { Concentrations }>6 \mathrm{ng} / \mathrm{ml} \text { have high sensitivity for unfavourable outcome and signify considerable risk of death } \\
\text { for patients admitted to the ED }\end{array}$ \\
{$[11]$} & $\begin{array}{l}\text { Concentrations }<4 \mathrm{ng} / \mathrm{ml} \text { have high NPV for unfavourable outcome and allow discharge of the patient from } \\
\text { the ED }\end{array}$ \\
{$[14]$} & $\begin{array}{l}\text { Concentrations }<12 \mathrm{ng} / \mathrm{ml} \text { for patients with infections and systemic inflammatory response syndrome have } \\
\text { high NPV for unfavourable outcome after } 28 \text { days }\end{array}$ \\
\hline $\begin{array}{l}\text { Reference } \\
\text { Limitations }\end{array}$ \\
$\begin{array}{l}\text { Non-specific for certain disease entities } \\
{[3-6]}\end{array} \quad \begin{array}{l}\text { Comorbidities such as chronic renal disease, HIV infection, solid tumour malignancy increase baseline levels } \\
{[10]}\end{array} \quad \begin{array}{l}\text { Concentrations between } 4 \text { and } 6 \mathrm{ng} / \mathrm{ml} \text { do not clearly indicate the risk of unfavourable outcome for patients } \\
\text { admitted to the ED }\end{array}$
\end{tabular}

$H I V$ human immunodeficiency virus, $N P V$ negative predictive value

regarding the utility of suPAR for patients admitted to the ED was made:

- sUPAR is a non-specific marker associated with a high negative predictive value for unfavourable outcome.

- Levels $<4 \mathrm{ng} / \mathrm{ml}$ allow discharge of the patient admitted to the ED after thorough clinical evaluation.

- Levels $>6 \mathrm{ng} / \mathrm{ml}$ are an alarming sign of risk for unfavourable outcome but they need to be interpreted in light of the patient's history.

- Levels between 4 and $6 \mathrm{ng} / \mathrm{ml}$ need to be interpreted in light of the patient's history of comorbidities, which may increase them, such as rheumatoid arthritis, solid tumour malignancy and chronic renal disease.

- Levels $>12 \mathrm{ng} / \mathrm{ml}$ in critically ill patients are prognostic of 28-day mortality ranging between 17 and 50\% depending on the APACHE II score.

- Levels $>12 \mathrm{ng} / \mathrm{ml}$ in a patient with suspicion of infection and one sign of the qSOFA score may be indicative of sepsis and unfavourable outcome.
- No strong evidence is available yet to support the use of suPAR as a surrogate tool for antimicrobial stewardship.

\section{SUGGESTED ALGORITHM}

It is emphasized that the diagnostic and prognostic utilities of suPAR have not been evaluated by any panel of international guidelines and that the GRADE system of recommendations has not been applied yet to validate suPAR. The panel of experts participating in this position paper ended up using an algorithm for the daily use of suPAR according to the level of patient management (ED, general ward, intensive care unit), which is presented in Fig. 1 and Table 1 summarizing the strengths and the weaknesses of this biomarker. There are still challenges to the interpretation of both suPAR and qSOFA in the ED, which require further research. These include: (1) NPV of suPAR < $4 \mathrm{ng} / \mathrm{ml}$ when qSOFA $=1$; (2) clear-cut definitions of moderate and low risk of death as depicted in Fig. 1. On-going trials are anticipated to provide concrete answers to these 
Table 2 Available and on-going studies on the role of suPAR for diagnosis and treatment guidance in the acute care setting. Results are from a search of Clinicaltrials.gov

\begin{tabular}{|c|c|c|c|c|c|c|}
\hline NCT number & Acronym & Brief title & Status & Design & Setting & $\begin{array}{l}\text { Target } \\
\text { patients }\end{array}$ \\
\hline NCT02643459 & TRIAGE & $\begin{array}{l}\text { Risk stratification in acute care: } \\
\text { the meaning of suPAR } \\
\text { measurement in triage }\end{array}$ & Completed & $\begin{array}{l}\text { Randomized } \\
\text { SOC; no suPAR } \\
\text { suPAR known }\end{array}$ & $\begin{array}{l}\text { ED in two } \\
\text { hospitals } \\
\text { in } \\
\text { Denmark }\end{array}$ & 20,000 \\
\hline NCT03147352 & ProTreat & $\begin{array}{l}\text { Prognosis and treatment of } \\
\text { necrotizing soft tissue } \\
\text { infections: a prospective } \\
\text { cohort study }\end{array}$ & Completed & $\begin{array}{l}\text { Intervention with } \\
\text { hyperbaric } \\
\text { oxygen }\end{array}$ & $\begin{array}{l}\text { Surgical } \\
\text { ward in } \\
\text { two } \\
\text { hospitals } \\
\text { in } \\
\text { Denmark }\end{array}$ & 260 \\
\hline NCT03717350 & SUPERIOR & $\begin{array}{l}\text { suPAR to guide antibiotics in } \\
\text { emergency department }\end{array}$ & Ongoing & $\begin{array}{l}\text { Randomized based } \\
\text { on suPAR levels } \\
\text { Placebo } \\
\text { Meropenem }\end{array}$ & $\begin{array}{l}\text { ED in two } \\
\text { hospitals } \\
\text { in Greece }\end{array}$ & 244 \\
\hline NCT04357366 & SAVE & $\begin{array}{l}\text { suPAR-guided anakinra } \\
\text { treatment for validation of } \\
\text { the risk and management of } \\
\text { respiratory failure by } \\
\text { COVID-19 }\end{array}$ & Ongoing & $\begin{array}{l}\text { Open-label } \\
\text { anakinra for } \\
\text { patients with } \\
\text { Covid-19 and } \\
\text { suPAR } \geq 6 \mathrm{ng} / \\
\text { ml }\end{array}$ & $\begin{array}{l}\text { General } \\
\text { wards in } \\
14 \\
\text { hospitals } \\
\text { in Greece }\end{array}$ & 100 \\
\hline NCT03249597 & NA & $\begin{array}{l}\text { Predict sepsis: the predictive } \\
\text { values of bedside } \\
\text { measurement in the } \\
\text { ambulance }\end{array}$ & Ongoing & Observational & $\begin{array}{l}\text { Four study } \\
\text { sites in } \\
\text { Sweden }\end{array}$ & 648 \\
\hline
\end{tabular}

$E D$ emergency department, $N A$ non-available, $S O C$ standard of care

questions. Table 2 provides a summary of the available and ongoing studies on the utility of suPAR as either a diagnostic tool or treatment guidance in the acute care setting after a search at Clinicaltrials.gov.

\section{ACKNOWLEDGEMENTS}

Funding. The study was funded by the Hellenic Sepsis Study Group; the funders supported the cost of meetings. No funding or sponsorship was received for the publication of this article.

Authorship. All named authors meet the International Committee of Medical Journal Editors (ICMJE) criteria for authorship for this article, take responsibility for the integrity of the work as a whole, and have given their approval for this version to be published.

Disclosures. Evangelos J. Giamarellos-Bourboulis has received honoraria from AbbVie USA, Abbott $\mathrm{CH}$, Biotest Germany, InflaRx GmbH, 
MSD Greece, XBiotech Inc. and Angelini Italy (paid to the University of Athens); independent educational grants from AbbVie, Abbott, Astellas Pharma Europe, AxisShield, bioMérieux Inc, InflaRx GmbH, Virogates AG and XBiotech Inc; funding from the FrameWork 7 programme HemoSpec (granted to the National and Kapodistrian University of Athens), the Horizon2020 Marie-Curie Project European Sepsis Academy (granted to the National and Kapodistrian University of Athens) and the Horizon 2020 European Grant ImmunoSep (granted to the Hellenic Institute for the Study of Sepsis). Evangelos J. Giamarellos-Bourboulis is a member of the journal's Editorial Board. Dimitrios Velissaris, George Dimopoulos, John Parissis, Zoi Alexiou, Nikolaos Antonakos, Dimitrios Babalis, Styliani Gerakari, Vassileios Kaldis, Pantelis Koutoukas, Malvina Lada, Konstantinos Leventogiannis, Ioannis Pantazopoulos, Antonios Papadopoulos, Eftihia Polyzogopoulou, Charalambos Gogos and Apostolos Armaganidis report no disclosures.

Compliance with Ethics Guidelines. This article is based on previously conducted studies and does not contain any studies with human participants or animals performed by any of the authors.

Data Availability. Data sharing is not applicable to this article as no datasets were generated or analyzed during the current study.

Open Access. This article is licensed under a Creative Commons Attribution-NonCommercial 4.0 International License, which permits any non-commercial use, sharing, adaptation, distribution and reproduction in any medium or format, as long as you give appropriate credit to the original author(s) and the source, provide a link to the Creative Commons licence, and indicate if changes were made. The images or other third party material in this article are included in the article's Creative Commons licence, unless indicated otherwise in a credit line to the material. If material is not included in the article's Creative Commons licence and your intended use is not permitted by statutory regulation or exceeds the permitted use, you will need to obtain permission directly from the copyright holder.To view a copy of this licence, visit http://creativecommons.org/licenses/by$\mathrm{nc} / 4.0 /$

\section{REFERENCES}

1. Eugen-Olsen J, Giamarellos-Bourboulis EJ. suPAR: the unspecific marker for disease presence, severity and prognosis. Int J Antimicrob Agents. 2015;46S: S33-S34.

2. Dinesh P, Rassol M. uPAR/suPAR signaling in rheumatoid arthritis: shedding light on its mechanism of action. Pharmacol Res. 2018;134:31-9.

3. Liu KL, Fan JH, Wu J. Prognostic role of circulating soluble UPAR in various cancers: a systematic review and meta-analysis. Clin Lab. 2017;63:871-80.

4. de Bock CE, Wang Y. Clinical significance of urokinase-type plasminogen activator receptor (UPAR) expression in cancer. Med Res Rev. 2004;24: 13-39.

5. Chounta A, Ellinas C, Tzanetakou V, et al. Serum soluble urokinase plasminogen actvator receptor as a screening tool for the early diagnosis of hepatocellular carcinoma. Liver Int. 2015;35:601-7.

6. Hayek SS, Sever S, Ko YA, et al. Soluble urokinase receptor and chronic kidney disease. N Engl J Med. 2015;373:1916-25.

7. Hayek SS, Leaf DE, Samman Tahhan A, et al. Soluble urokinase receptor and acute kidney disease. N Engl J Med. 2020;382:416-26.

8. Hayek SS, Koh $\mathrm{KH}$, Graims ME, et al. A tripartite complex of suPAR, APOL1 risk variants and $\alpha_{v} \beta_{3}$ mediates chronic kidney disease. Nat Med. 2017;23: 945-53.

9. Winnick W, Sunder-Plassmann G, Sengölge G, et al. Diagnostic and prognostic value of soluble urokinase-type plasminogen activator receptor (suPAR) in focal segmental glomelurosclerosis and impact of detection method. Sci Rep. 2019;9:13783.

10. Schultz M, Raamussen LJH, Kallemose T, et al. Availability of suPAR in emergency departments may improve risk stratification: a secondary analysis of the TRIAGE III trial. Scand J Traum Res Emerg Med. 2019;27:43.

11. Schultz M, Rasmussen LJH, Høi-Hansen T, et al. Early discharge from the emergency department based on soluble urokinase plasminogen activator 
receptor (suPAR) levels: a TRIAGE III substudy. Dis Markers. 2019;2019:3403549.

12. Velissaris D, Pierrakos C, Karamouzos V, Pantzaris ND, Gogos C. The use of soluble urokinase plasminogen activator receptor (suPAR) as a marker of sepsis in the emergency department setting. A current review. Acta Clin Belg. 2019;21:1-6.

13. Rovina N, Akinosoglou K, Eugen-Olsen J, Salim H, Reiser J, Giamarellos-Bourboulis EJ. Soluble urokinase plasminogen activator receptor (suPAR) as an early predictor of severe respiratory failure in patients with COVID-19 pneumonia. Crit Care. 2020; 24: 187

14. Savva A, Raftogiannis M, Baziaka F, et al. Soluble urokinase plasminogen activator receptor (suPAR) for assessment of disease severity in ventilator-associated pneumonia and sepsis. J Infect. 2011;63: 344-50.

15. Giamarellos-Bourboulis EJ, Norrby-Teglund A, Mylona V, et al. Risk assessment in sepsis: a new prognostication score by APACHE II score and serum soluble urokinase plasminogen activator receptor. Crit Care. 2012;16:R149.

16. Kumar A, Roberts D, Wood KE, et al. Duration of hypotension before initiation of effective antimicrobial therapy is the critical determinant of survival in human septic shock. Crit Care Med. 2006;34:1589-96.

17. Singer M, Deutschman CS, Seymour CW, et al. The third international consensus definitions for sepsis and septic shock (Sepsis-3). JAMA. 2016;315: 801-10.

18. Giamarellos-Bourboulis EJ, Tsaganos T, Tsangaris I, et al. Validation of the new Sepsis-3 definitions: proposal for improvement in early risk identification. Clin Microbiol Infect. 2017;23:104-9.

19. A suPAR-guided double-blind randomized clinical trial of initiation of antibiotics for presumed infection at the emergency department. https:// clinicaltrials.gov/ct2/show/NCT03717350. 